\title{
The burden and underlying determinants of under nutrition among under five year children in Gurage Zone
}

\author{
Andamlak Dendir Egata ${ }^{1}$, Abdusemed Worku Nida ${ }^{2}$ \\ ${ }^{1}$ Lecturer in Department of Public Health, College of Medicine and Health Sciences, Wolkite University, Wolkite, \\ Ethiopia, ${ }^{2}$ Medical Doctor in Department of Medicine, College of Medicine and Health Sciences, Wolkite University, \\ Wolkite
}

Background: Malnutrition is one of the most common causes of morbidity and mortality in children under the age of five year. However, In Gurage zone Information about the prevalence and associated factors of malnutrition still limited. Aims and Objectives: The major objective of this study was assessing the burden and determinants of malnutrition among under five children. Materials and Methods: A community based cross-sectional study design was applied from December 25, 2016 to April 25, 2017. A total of 1040 eligible mothers were interviewed using structured interviewer administered questionnaires by trained data collectors working in pediatrics ward. Through systematic sampling technique study participant were included in the study. To test the existence of statistical relationship between independent and dependent variables multiple logistic regressions analysis was used. Results: The prevalence of malnutrition among study children was $38.8 \%$. Logistic regressions analysis result indicated that Unimproved sanitation [AOR $1.58(95 \% \mathrm{Cl} 1.13-2.2)]$, food insecurity [AOR 2.06 (Cl 3.49-3.33)], maternal disempowerment [AOR 4.1(Cl 2.69-6.24)], inadequate frequency of exclusive breast feeding [AOR 1.9 (95\% Cl 1.176-3.357]. showed a significant association with malnutrition. Conclusion: The prevalence of malnutrition among under five year children living in Gurage zone was $38.8 \%$. It was associated with utilization of unimproved sanitation, maternal disempowerment, food insecurity. Hence to abort the problem, it is better to enhance house hold food security, exclusive breast feeding, maternal empowerment and utilization of improved sanitation.

Key words: Malnutrition; Determinants of undernutrition; Burden of undernutrition in Gurage Zone

\section{INTRODUCTION}

The World Health Organization (WHO) defines malnutrition as a cellular imbalance between supply of nutrients and the body's demand for them. Malnutrition is a health outcome as well as it can increase the risk of both morbidity and mortality associated with other disease ${ }^{1}$

Globally, malnutrition is one of the most common causes of morbidity and mortality in children under the age of five years. ${ }^{2}$ Forty five percent (45\%) of all child deaths that occurred in the world directly and indirectly associated with malnutrition. In support of this, of 6.9 million of death that occurred globally 3.1 million were associated with malnutrition. ${ }^{3}$ In 2011, 165 million children were stunted, 101 million children were under weight, 52 million were wasted worldwide. Africa and Asia account the ninety percent of $(90 \%)$ of this statistics. ${ }^{4}$

In Africa, Ethiopia is the second-most populous country that inhabits approximately 83 million people and of these; around $14 \%$ of them were children under five years of age. ${ }^{5}$ These children and their mothers were suffering disproportionately from poor health and nutrition in the 
country. ${ }^{6}$ In 2014 nationally 44\%, 25\% and 9\% of children under the age of five year were underweight and wasted respectively. ${ }^{7}$ In addition, in Ethiopia $51 \%$ of deaths that occurred among under five years children were associated with malnutrition. ${ }^{7}$ In 2014, 44\%, 26\% and 7\% of under year's children living in Southern part of Ethiopia were stunted, underweight and wasted respectively. ${ }^{7}$

The risk factors of malnutrition are multifaceted and complex. Besides, relative importance of each of the known risk factors is can vary from region to region and country to country. It has long been recognized that poor socioeconomic status, low education, sub-optimal nutrition and poor environmental and personal hygiene condition, poor nutritional status of the mother as a major risk factors of malnutrition but the relative importance of each of the known risk factors are can vary from set up to set up. There were a multiple of epidemiological studies done on determinants of childhood malnutrition but none of them simultaneously examine the role of food insecurity and maternal disempowerment on the risk of malnutrition. Besides, to the best of authors knowledge there is no empirical study done to assess the prevalence of malnutrition in Gurage zone. Hence, this study aimed to determine the prevalence and the determinates of malnutrition in Gurage zone.

\section{METHODS AND MATERIALS}

\section{Study area}

The study was conducted within community of Gurage zone which is located in southern region of Ethiopia with a total population of 1,279,646 (622,078 were men and 657,568 were women). The livelihoods of the residents were mainly based on agricultural product. Currently, the zone has one general hospital and different private and governmental health institution that has been offering different health care services.

\section{Study design}

A community based cross-sectional study design was applied from December 25, 2016 to April 25, 2017.used to describe the prevalence and associated factors of malnutrition.

\section{Study population}

All under five year children living in selected districts of Gurage zone were considered as study populations.

\section{Inclusion and exclusion criteria}

Those under five year children who had a mother who lived in Gurage zone for a minimum of six month were included in the study but Orphan children or children separated from his or her mother by various reasons were excluded from the study.

\section{Sample size determination}

The required sample size was determined through EPI INFO version 7.0 software. Since one of the objective was to determine the prevalence of malnutrition, single population proportion formulas with the following assumption i.e confidence levels of $95 \%$, prevalence of wasting $13 \%$, margin of error 3\% was used. Based on the above assumptions, with additional $10 \%$ for non response rate and design effect of 2 the total sample size calculated was 1062 .

\section{Sampling technique and procedure}

Since, the zone has a total of thirteen homogenous districts, four of the districts (Cheha, Enemor and Ener, Meskan and Abeshge Districts), which accounts about 31\% of the districts, were randomly chosen. Then, the calculated sample size was proportionally allocated to each selected districts. Since kebele (the lowest subdivision district) within selected districts are homogenous, about $25 \%$ of them were selected through lottery methods. Before selecting the study sampling frame was created through direct numbering of eligible households in the kebele. Finally, using sampling frame a total of 1062 participants were picked through lottery method.If more than one child was living in a single household and picked during selection, one of the child was included through lottery methods.

\section{Study variables}

household food security status, household maternal empowerment status, maternal height, maternal age, maternal occupation, educational level of the mother, access to improved water sources, sanitation, flooring type of the household, sex of the child, age of the child, birth order of the child, twinning religion, residence were considered as explanatory variables of the study where as malnutrition is the outcome variable of the study. To this study malnutrition means height for age $Z$-score or weight for height Z- score or weight for age Z-score less than -2 SD. Household Adequate Access to improved source of water was defined as Getting water 20 lit water/c/d for urban Vs 151 safe water/cl/d for rural household from piped, protected ground water (wells, springs) source within one kilometer or $<15$ minute which is enough for daily need. A sanitation that constitutes one of the following: connection to a public sewer, connection to a septic tank system, pour-flush toilet, hygienic pit toilet, ventilated improved pit (VIP) toilet were categorized as improved sanitation (8) whereas a sanitation options which are not considered "improved" which include: Public or shared toilet, open pit toilet, Bucket toilet were defined as Unimproved sanitation (9). In addition, those mother who lack the autonomy to decide alone or jointly with her husband in any of the following three decisions making process:-her own and child health care, allocation of 
household resource/household expenditure,and to visit their relatives(family) or health institution were diagnosed as disempowered mother.

\section{Data collection techniques and quality assurance}

The mothers of the selected children were interviewed using structured and interviewer administered questionnaire. The questionnaire incorporates questions that could measure maternal empowerment, socio-economic and demographic factors, child characteristics, maternal characteristics, environmental health and household food security status well. The English version questionnaire was translated in to Amharic version for common understanding. The nutritional status of the children was measured through anthropometric measurements. Weight scale was used to measure the weight and height of children. Measuring board instruments was used to measure the height of children aged below two. To assure the validity of the scale, the weight of the participants was measured in undressed or with minimum clothing, the weighting scales was calibrated with known weight object regularly and three data collector were assigned to measure the height and weight of the child. The scale indicator was checked against zero reading after weighing every child.

The questionnaire was pre- tested on 53 children ( $5 \%$ of the sample size) living in a population out of study population. To assure the quality of data, data collectors and supervisor got intensive two day training on objective of the study, procedure and technique of data collection. The supervisor and investigators closely monitors the data collectors.

\section{Data processing and analysis}

Using Statistical Package for Social Sciences version 21 (SPSS) data cleaning, recoding, categorizing and analyzing were done. Anthropometric data were analyzed through Emergency Nutrition Assessment software (ENA). Other statistical analysis was done by SPSS version 21. Through interviewing three questions that could measure the autonomy of the mother on decision related to resource allocation, own and child health care and mobility, maternal empowerment was measured. Household food insecurity status of the participants was assessed by using nine generic questions of Household Food Insecurity Access Scale (HFIAS) which was developed by USAID Food and Nutrition Technical Assistance (FANTA) (36). Through using this scale household food insecurity were categorized into four level i.e Foods secure, and mild, moderately and severely food insecure). To summarize the distribution of each variables mean, frequency and percentage of the variable were calculated. To evaluate the association between a single independent variable with dependent variable Crude Odds Ratio were used. To adjust the effect of confounder variables that had $\mathrm{p}$-value less than 0.05 were entered in multiple logistic regressions analysis. To test the observed association is statistically significant or not $95 \%$ CI was used.

\section{Ethical consideration}

Since the study procedure didn't undergone immoral and invasive procedures, letter of permission were obtained from the research ethics committee of Wolkite University. Cooperation letter to district health office was gained from Gurage Zone health bureau. After the study participants got clear explanation on the objective, risk and benefit of the research work their verbal consent was obtained.

\section{RESULTS}

A total of 1062 child-mother pairs were planned to be studied but only 1040 child-mother pairs were happy for the invitation. This gives us overall response rate of $99.4 \%$.

\section{Socio-demographic characteristics}

Of 1040 children who were included in the analysis almost half of them (47.8\%) were Muslim; the rests were followers of orthodox (40.6\%) and protestant (11.6\%) religion. Looking at the age structure of participants, about eighty three percent of $(83.6 \%)$ mothers found within age range of 18 and 35 years where as sixteen percent $(16.3 \%)$ and $0.2 \%$ of the mothers were within age group greater than 35 and less than eighteen years respectively. Most of the study children were aged 6 month and above. Pertaining parental educational status about 39.9 percent of mother and sixty percent $(60.4 \%)$ of father had primary and above level of education. regarding to parental occupation the majority of mother $(88.6 \%)$ were housewife and eighty four percent $(87.1 \%)$ of father were farmer.

Of 1035 participants, only sixty five percent $(65.1 \%)$ of them were living in food secured household. The rest $7.3 \%$, $18.3 \%$ and $9.3 \%$ of participants were living in household with mild, moderate and severe type food insecurity.

In relating to maternal empowerment status, fourteen percent $(14 \%)$ the mother were disempowered, twenty eight percent $(28.2 \%)$ were partially empowered and the rest fifty seven point eight percent $(57.8 \%)$ were empowered mother (see Table 1).

\section{Child characteristics}

In this study, the proportions of male and female children were more or less equal. Most of the study children were singleton and had age of 6 month and above. About fifty three percent $(53.6 \%)$ of the children had fourth and above birth order. This study indicated that from a total of 1035 under five children, $400(38.8 \%)$ of them had malnutrition (see Table 2). 


\begin{tabular}{|c|c|c|c|}
\hline $\begin{array}{l}\text { Explanatory } \\
\text { variables }\end{array}$ & Category & Case & Control \\
\hline \multirow[t]{3}{*}{ Maternal age group } & $<18 y r s$ & 1 & 7 \\
\hline & $18-35$ yrs & 119 & 239 \\
\hline & $>35$ yrs & 11 & 11 \\
\hline \multirow[t]{4}{*}{ Religion } & Ortodox & 63 & 133 \\
\hline & Catholic & 9 & 11 \\
\hline & Protestant & 13 & 32 \\
\hline & Muslim & 46 & 89 \\
\hline \multirow[t]{4}{*}{ Maternal occupation } & Employee & 20 & 31 \\
\hline & Farmer & 15 & 27 \\
\hline & Merchant & 11 & 24 \\
\hline & Housewife & 85 & 183 \\
\hline \multirow[t]{2}{*}{$\begin{array}{l}\text { Maternal educational } \\
\text { status }\end{array}$} & $\begin{array}{l}\text { Had formal } \\
\text { education }\end{array}$ & 90 & 170 \\
\hline & $\begin{array}{l}\text { Had no formal } \\
\text { education }\end{array}$ & 41 & 95 \\
\hline \multirow{4}{*}{$\begin{array}{l}\text { Maternal level of } \\
\text { education }\end{array}$} & Primary & 61 & 100 \\
\hline & Secondary & 7 & 45 \\
\hline & Diploma & 9 & 12 \\
\hline & Degree and above & 13 & 13 \\
\hline \multirow[t]{2}{*}{$\begin{array}{l}\text { Paternal educational } \\
\text { status }\end{array}$} & $\begin{array}{l}\text { Had formal } \\
\text { education }\end{array}$ & 101 & 197 \\
\hline & $\begin{array}{l}\text { Had no formal } \\
\text { education }\end{array}$ & 30 & 67 \\
\hline \multirow{4}{*}{$\begin{array}{l}\text { Paternal level of } \\
\text { education }\end{array}$} & Primary & 46 & 103 \\
\hline & Secondary & 26 & 55 \\
\hline & Diploma & 9 & 10 \\
\hline & Degree and above & 20 & 29 \\
\hline \multirow[t]{4}{*}{ Paternal occupation } & Employee & 38 & 56 \\
\hline & Farmer & 70 & 137 \\
\hline & Merchant & 13 & 51 \\
\hline & Other & 10 & 20 \\
\hline
\end{tabular}

\section{Environmental and child feeding practice}

Out of 1034 study participant, sixty-one percent of them $(61.7 \%)$ had adequate access to improved source of water. about fifty seven percent of them had improved sanitation where as the rest (42.7) \% of household had no improved sanitation. Moreover, majority of study children (95\%) lived in household with muddy floor. Concerning breast feeding, about seventy percent $(69.9 \%)$ of participants practiced exclusive breast feeding; about ninety two percent (91.7\%) of mother gave exclusive breast feeding greater than or equal to eight times per day. (see Table 3).

\section{Factors associated with malnutrition}

Multivariate logistic regression analysis revealed that, lack of improved sanitation, not practicing exclusive breast feeding, food insecurity and maternal disempowerment were significantly associated with malnutrition.

Those children who had disempowered mother had 3.9 times higher risk of developing malnutrition compared to children with empowered mother)], [AOR 3.9 (95\% CI 2.69-6.24)].

\begin{tabular}{llcc}
\multicolumn{3}{l}{$\begin{array}{l}\text { Table 2 : Characteristics of the study children in } \\
\text { Gurage Zone, SNNPR, April 2016. }\end{array}$} \\
$\begin{array}{llcc}\text { Child } \\
\text { characteristics }\end{array}$ & Category & Frequency & Percentage \\
\hline Sex & Male & 540 & 52.0 \\
& Female & 498 & 48.0 \\
Age group & Total & 1038 & 100.0 \\
& $<6$ month & 70 & 6.7 \\
& [6month-24) & 399 & 38.4 \\
& [24-36) & 256 & 24.7 \\
& [36-59) & 313 & 30.2 \\
Birth order & Total & 1038 & 100.0 \\
& First & 122 & 11.9 \\
& Second & 164 & 15.9 \\
& Third & 191 & 18.6 \\
\multirow{4}{*}{ Twining } & Fourth & 552 & 53.6 \\
& Total & 1029 & 100.0 \\
\multirow{4}{*}{ Child Nutritional } & Twin & 12 & 1.2 \\
status & Singleton & 1002 & 98.8 \\
& Total & 1014 & 100.0 \\
& Malnourished & 400 & 38.8 \\
& Malnurished & & \\
& Normal & 631 & 61.2 \\
& & 1031 & 100 \\
\hline
\end{tabular}

\begin{tabular}{|c|c|c|c|}
\hline $\begin{array}{l}\text { Explanatory } \\
\text { variables }\end{array}$ & Category & Frequency & Percentage \\
\hline \multirow{3}{*}{$\begin{array}{l}\text { Practice of } \\
\text { exclusive breast } \\
\text { feeding }\end{array}$} & Practiced & 717 & 69.4 \\
\hline & Not practiced & 316 & 30.6 \\
\hline & Total & 1033 & 100 \\
\hline \multirow{3}{*}{$\begin{array}{l}\text { Frequency of } \\
\text { exclusive feeding }\end{array}$} & $<8$ times & 85 & 8.3 \\
\hline & $>=$ Eight times & 941 & 91.7 \\
\hline & Total & 1026 & 100 \\
\hline \multirow{3}{*}{$\begin{array}{l}\text { Adequate Access } \\
\text { to improved } \\
\text { water supply }\end{array}$} & Had access & 642 & 62.7 \\
\hline & Had no access & 382 & 37.3 \\
\hline & Total & 1024 & 100 \\
\hline \multirow[t]{3}{*}{ Sanitation type } & Improved & 592 & 57.3 \\
\hline & Unimproved & 442 & 42.7 \\
\hline & Total & 1034 & 100 \\
\hline \multirow[t]{3}{*}{ Floor type } & Mud & 986 & 95 \\
\hline & Cement & 52 & 5 \\
\hline & Total & 1038 & 100 \\
\hline
\end{tabular}

Comparing to children living in food secured household, children living in a household with moderate and sever food insecurity had higher chance of getting malnutrition. Those children living in severely and moderately food insecured household had about two times more likely to develop malnutrition [AOR 2.06 (95\% CI 3.49-3.33)] and [AOR 2.00 (95\% CI 2.882-1.365)]. In this study, mild household food insecurity didn't show a statistical relationship with malnutrition

This study also demonstrated that children who didn't practice exclusive breast feeding had 1.44 times more likely to have malnutrition compared to children who practiced exclusive breast feeding [AOR 1.44 (95\% CI 
1.05-1.97)]. children living in households who didn't had had 1.58 times more likely to develop malnutrition [AOR 1.58 (95\% CI 1.13-2.25)] than children living in household with improved sanitation. Children who experienced inadequate frequency of exclusive breast feeding had about two time's higher risk of malnutrition [AOR 1.9 (95\% CI 1.176-3.357]. In this study, we didn't got enough evidence showing the association between access to adequate improved water source and malnutrition (see Table4).

\section{DISCUSSION}

By using a cross-sectional study design, this study assessed the prevalence and associated factors of malnutrition in Gurage zone. The study revealed that, the prevalence of malnutrition in study area was $38.8 \%$ and it was associated with lack of improved sanitation, not practicing appropriate exclusive breast feeding, food insecurity and maternal disempowerment.

Comparing to other prevalence study finding done in west Gojam zone and Dollo Ado district of Somalia region, the burden of malnutrition here in study area was high. ${ }^{8}$ This may be attributed to variation in climate, human development efforts, variation in distribution of socio demographic factors that has a strong association with children's' nutritional status. However, the finding of this study was very consistent with study done on Bule Hora districts of Southern Ethiopia. ${ }^{9}$ The magnitude of malnutrition in Iran is lower than the magnitude in this study area. ${ }^{10}$ The best explanation for the disagreement may be due to, introduction of successful public health interventions undertaken by government and nongovernmental organization in Iran, variation in social and human development.

Comparing to children who were living in household with improved sanitation, children living in households with unimproved sanitation had 1.58 times more likely to develop malnutrition. This variation might be due to children living in household with unimproved sanitation have more chance of exposure for repeated infections like diarrhea, intestinal parasitosis and other fecal born disease which ultimately compromises the nutrient intake of the growing child. This finding is in line with study done in Bola Hora Distracts in Somalia region of Ethiopia and Kwara State of Nigeria. ${ }^{910}$ However, studies done in southern and North West of Ethiopia sanitation had no a valid statistical association with malnutrition. ${ }^{11,12}$ The variation may be because of different technical definition applied for sanitation or the context.

\begin{tabular}{|c|c|c|c|c|c|c|c|}
\hline \multirow[t]{2}{*}{ Explanatory variables } & & \multicolumn{2}{|c|}{ Malnutrition } & \multirow[t]{2}{*}{ Per COR $(95 \% \mathrm{Cl})$} & \multirow[t]{2}{*}{ AOR tage } & \multicolumn{2}{|c|}{$95 \% \mathrm{Cl}$ for AOR } \\
\hline & & No & Yes & & & Lower & Upper \\
\hline \multirow[t]{3}{*}{ maternal empowerment status } & Disempowered & 52 & 88 & $\begin{array}{l}4.582(3.104 \\
6.765)\end{array}$ & 3.952 & 2.606 & 5.991 \\
\hline & Partially Empowered & 135 & 146 & $\begin{array}{l}2.928(2.173 \\
3.946)\end{array}$ & 2.704 & 1.970 & 3.712 \\
\hline & Empowered & 417 & 154 & 1.00 & 1.00 & - & - \\
\hline \multirow{4}{*}{ Level of food insecurity } & Food secured & 449 & 218 & & 1.00 & - & - \\
\hline & Mild food insecurity & 42 & 34 & $\begin{array}{l}1.667(1.031 \\
2.695)\end{array}$ & 0.867 & 2.534 & 0.867 \\
\hline & Moderate food insecurity & 96 & 91 & $\begin{array}{l}1.952(1.405 \\
2.714)\end{array}$ & 2.008 & 2.882 & 1.365 \\
\hline & Sever food insecurity & 42 & 54 & $\begin{array}{l}2.648(1.715 \\
4.089)\end{array}$ & 2.009 & 3.490 & 1.339 \\
\hline \multirow[t]{2}{*}{ Practice of exclusive breast feeding } & Practiced & 473 & 239 & 1.00 & 1.00 & - & - \\
\hline & Not practiced & 153 & 160 & $\begin{array}{l}2.070(1.579 \\
2.713)\end{array}$ & 1.448 & 1.060 & 1.977 \\
\hline \multirow[t]{2}{*}{ Frequency of exclusive feeding } & $<8$ times & 30 & 53 & $\begin{array}{c}3.049(1.911 \\
4.865)\end{array}$ & 1.987 & 1.176 & 3.357 \\
\hline & $>=$ Eight times & 592 & 343 & 1.00 & 1.00 & - & - \\
\hline \multirow{2}{*}{$\begin{array}{l}\text { Adequate Access to improved water } \\
\text { supply }\end{array}$} & Had access & 387 & 248 & 1.00 & 1.00 & - & - \\
\hline & Had no access & 236 & 144 & $\begin{array}{l}0.952(0.773 \\
1.237)\end{array}$ & & & \\
\hline \multirow[t]{2}{*}{ Sanitation type } & Improved & 404 & 183 & 1.00 & 1.00 & - & - \\
\hline & Unimproved & 225 & 213 & $\begin{array}{l}2.090(1.618 \\
2.700)\end{array}$ & 1.584 & 1.180 & 2.126 \\
\hline \multirow[t]{2}{*}{ Floor type } & Mud & 589 & 388 & $\begin{array}{l}2.196(1.138 \\
4.239)\end{array}$ & 1.889 & 0.877 & 4.068 \\
\hline & Cement & 40 & 12 & 1.00 & 1.00 & - & - \\
\hline
\end{tabular}


Those children who didn't practice exclusive breast feeding had 1.4 times more likely to develop malnutrition compared to children who practiced exclusive breast feeding. This can be best explained by the fact that, till six months exclusive breast milk can prevent repeated infection through providing all of the necessary nutrients for healthy development; through providing important antibodies against common childhood illnesses and through preventing babies from ingesting contaminated water that could be mixed with infant formula. Hence, lack of this opportunity may compromise the nutritional status of the children. Encouragingly, this finding was in line with studies done in different part of Ethiopia, Bangladesh and Nepal. ${ }^{9,11-19}$

Malnutrition in this study area didn't show a significant association with Access to adequate source of improved water. This statistically insignificance result can be best explained by due to the majority of population in both malnourished and well nourished group had access to adequate source of water.

This study also indicated that children living in household with sever food insecurity had 2.1 times more chance of developing malnutrition compared to children living in food secured household. This risk dissimilarity may be due to the fact that children living in household with severe food insecurity can have more chance for inadequate food intakes, eating poor-quality food, and to have disrupted eating patterns. Compared to study done in different part of the world this finding was very consistent with studies done in Nepal, East-Central Uganda, and Colombia. ${ }^{20-26}$ However, this finding was not in line with the finding of other similar studies done in east rural Ethiopia which revealed that food insecurity had no significant association with malnutrition. ${ }^{9}, 27$ This inconsistency might be due to the copying mechanism of mother living in food unsecured household which forces mother to reduce their own intakes to secure their infants and small children. The difference may also be explained by the high prevalence of food secured household and its insufficiency to secure the nutritional wellbeing of the children. Study done in slum area of South Africa also showed inconsistent result. This inconsistency may be due to the difference in measurement tools, use of convenient sampling technique which is a potential source of selection bias, and also may be due the copying mechanism of the setup.

Children of disempowered mother had 3.9 times more risk of malnutrition compared to those children with empowered mother. This might be best explained by the fact that, disempowered mothers do not have the autonomy to allocate the household resource for the preparation of adequate quantity of quality proofed food recommended for growing children, for utilization of the appropriate preventive (e.g. immunization) and curative (while their child get sick) health care service for their growing child. The observed difference may be also due to the fact that, disempowered mothers have less probability to utilize maternal health care services (antenatal, delivery care,postnatal care) and other medical care that are crucial to enhance the overall care of their children. ${ }^{28}$

This study has some strength and limitations. The sampling technique and the study design applied make the finding upon prevalence of malnutrition to be representative of the target population. However, since it applies a cross-sectional study design it is difficult to assure the temporal relationship between some independent variable and dependent variable.

\section{CONCLUSION AND RECOMMENDATIONS}

The prevalence of malnutrition among under five year children living in Gurage zone was $38.8 \%$. This public health problem was associated with utilization of unimproved sanitation, maternal disempowerment, food insecurity and not practicing exclusive breast feeding. Hence, this study implicated that the prevalence of malnutrition is high compared to other area. Hence, Gurage zone health department should abort the problem through enhancing food security status of the household, maternal empowerment, improved sanitation and exclusive breast feeding.

\section{Data availability}

The data generated or analyzed during the current study are available from the corresponding author on reasonable request.

\section{ACKNOWLEDGMENTS}

All authors would like to acknowledge Wolkite University for funding this research work. Since, This research work couldn't have been completed without cooperation of Gurage Zone Health department, we are very gratefully to express appreciation them. Finally, we are happy to express our deepest gratitude to the data collectors and study participants, because without their participation this study wouldn't be realized.

\section{REFERENCES}

1. Blössner $M$ and de Onis, Mercedes. Quantifying the health impact of malnutrition at national and local levels. Geneva: World Health Organization, 2005

2. National nutrition programme June 2013-june 2015: 2014, Addis Ababa. 
3. Black RE, Victora CG, Walker SP, Bhutta ZA, Christian PS, De Onis $M$, et al. Maternal and child under nutrition and overweight in low income and middle-income countries. Journal of Lancet.2013; 382(9890): 427-451.

4. Mercedes de Onis DB, Monika. Levels \& Trends in Child Malnutrition. Geneva World Health Organization and UNICEF, 2012.

5. The 2007 housing and population census of Ethiopia. Addis Ababa, Ethiopia Central Statistical Agency 2007.

6. Ethiopia: situation analysis for Transform Nutrition: 2013.

7. Ethiopia Demographic and Health Survey 2014. Addis Ababa, Ethiopia: Central Statistical Agency, 2014.

8. Demissie $S$ and Worku A. Magnitude and factors associated with malnutrition in children 6-59 months of age in pastoral community of Dollo Ado district, Somali region, Ethiopia. Science Journal of Public Health. 2013; 1(4):175-183.

9. Mandefro A, Mohammed T and Lamessa D. Prevalence of undernutrition and associated factors among children aged between six to fifty nine months in Bule Hora district, South Ethiopia. Journal of BioMedCentral Public Health. 2015; 15:14

10. Elham K, Rostami ZH, Kavosi Z, Nasihatkon A, Moghadami M and Heidari M. Prevalence and determinants of under-nutrition among children under six: a cross-sectional survey in Fars province, Iran. International Journal of Health Policy and Development. 2014; 3(2):7

11. Smith LC, Ramakrishnan U, Ndiaye A, Haddad L and Martorell R. The Importance of Women's Status for Child Nutrition in Developing Countries. Washington, DC: IFPRI 2003.

12. Sethuraman K. The Role of Women's Empowerment and Domestic Violence in Child Growth and Under nutrition in a Tribal and Rural Community International Center for Research on Women. 2008.

13. Saaka M and Osman M. Does Household Food Insecurity Affect the Nutritional Status of Preschool Children Aged 6-36 Months. International Journal of Population Research 2013.

14. Francis Lwanga RKW, Joseph KB Matovu and Orach CG. Food Security and Nutritional Status of Children Residing in Sugarcane Growing Communities of East-Central Uganda: A Crosssectional Study. Journal of Food Security 2015; 3(2): 34-39.

15. Üstün $P$ and Corvalán $C$. Preventing Disease through Healthy Environments: Towards an Estimate of the Environmental Burden of Disease. Geneva: World Health Organization, 2006.

16. Masiye F, Chama $C$ and Chitah B. Determinants of Child Nutritional Status in Zambia: An Analysis of a National Survey.
University of Zambia 2006.

17. Jejeebhoy S. Women's autonomy in rural India: Its dimensions, determinants and influence in the context of India: Women's empowerment and demographic processes. New York: Oxford University Press. 2000.

18. Gender Inequality and Women's Empowerment; In-depth Analysis of the Ethiopian Demographic and Health Survey 2005. Ethiopian Society of Population Studies. 2008.

19. UNICEF. "Strategy for Improved Nutrition of Children and Women in Developing countries». A Policy Review. New York. 1990.

20. Gudina E, Yemane B and Alemayehu W. Predictors of acute undernutrition among children aged 6 to 36 months in east rural Ethiopia: a community based nested case - control study. BMC Pediatrics 2014; 14:91.

21. Bantamen G. Assessment of Factors Associated with Malnutrition among under Five Years Age Children at Michael Worde, Northwest Ethiopia: A Case Control Study. Journal of Nutrition and Food Science 2014; 4:256.

22. de Villiers $A$ and Senekal M. Determinants of growth failure in 12-24-month-old children in a high-density urban slum community in East London, South Africa European Journal of Clinical Nutrition 2002; 56(12):1231-1241.

23. Olagunju F, Fakayode $S$ and Sola-Ojo F. Prevalence and Determinants of Malnutrition among Under-five Children of Farming Households in Kwara State, Nigeria. Journal of Agricultural Science 2011; 3(3):173.

24. WHO Collaborative Study Team on the Role of Breastfeeding on the Prevention of Infant Mortality. Effect of Breastfeeding on Infant and Child Mortality Due to Infectious Diseases in Less Developed Countries: A Pooled Analysis Lancet 2000

25. Teshale F, Sahilu A and Lamessa Dube. Factors associated with stunting among children of age 24 to 59 months in Meskan district, Gurage Zone, South Ethiopia a case-control study. Journal of BioMed Central Public Health 2014; 14:800.

26. Hong $R$, Banta $E$ and Betancourt J.Relationship between household wealth inequality and chronic childhood under-nutrition. International Journal for Equity in Health 2006; 5:15.

27. International Bank for Reconstruction and Development report 2008. Environmental health and child survival: epidemiology, economics, experiences. Washington, DC: World Bank, 2008.

28. Asian Development Bank. Gender equality and food security-women's empowerment as a tool against hunger Mandaluyong City, Philippines: Asian Development Bank, 2013.

\section{Authors Contribution:}

AD- Proposal development, statistical analysis, manuscript preparation; AWN- Supervision and coordination of the data collection process, proposal development, data analysis and edition of the first draft manuscript. Finally, all authors read and approved the final manuscript for its publication.

Work attributed to:

College of Medicine and Health Sciences, Wolkite University

Orcid ID:

Mr.Andamlak Dendir- https://orcid.org/0000-0001-7278-6186

Source of Support: This research was fully granted by Wolkite University, Conflict of Interest: None declared. 